\title{
Stereodifferentiation in the formation and decay of the encounter complex in bimolecular electron transfer with photoactivated acceptors $\dagger$
}

\author{
Received (in Cambridge, UK) 17th January 2005, Accepted 22nd April 2005 \\ First published as an Advance Article on the web 24th May 2005 \\ DOI: $10.1039 / b 500697 j$
}

Julia Pérez-Prieto, ${ }^{* a}$ Raquel E. Galian, ${ }^{a}$ Maria C. Morant-Miñana ${ }^{a}$ and Miguel A. Miranda ${ }^{* b}$

Experimental evidence has been obtained for the involvement of encounter complexes between both enantiomers of a $\pi, \pi^{*}$ triplet excited ketone and a chiral phenol or indole. Determination of the pre-equilibrium constants $\left(K_{\mathrm{EC}}\right)$ and the intrinsic decay rate constants $\left(k_{\mathrm{d}}\right)$ indicates a significant stereodifferentiation in both steps of the quenching process.

Encounter complexes are well-established intermediates in emission quenching and in photoreactions occurring from singlet and triplet excited states. ${ }^{1,2}$ In this context, Kochi et al. have shown that photoinduced electron transfer from alkylbenzenes to triplet quinones can be kinetically analyzed taking into account the twostep nature of the mechanism: encounter complex formation and subsequent internal electron transfer within this intermediate. ${ }^{3}$ Thus, the second-order quenching rate constant can be considered a composite of the pre-equilibrium constant and the intrinsic electron-transfer rate constant.

On the other hand, chiral recognition in the excited states has become a subject of increasing interest in photochemistry. ${ }^{1 a, 1 d, 2 c, 4}$ It has been reasoned ${ }^{5}$ and later demonstrated that the involvement of encounter complexes is an essential condition for asymmetry observation in emission quenching or photosensitization. Such observation could be limited either to the encounter complex formation or to its decay, but it could also occur in both steps. Then, it appeared of interest to explore the possible stereodifferentiation in the formation and decay of encounter complexes arising from the quenching of triplet excited states. To our knowledge, no analysis of this type has been reported as yet.

We have recently studied the intermolecular quenching of excited 2-benzoylthiophene (BT, $\pi, \pi^{*}$ triplet) by phenol and indole. ${ }^{6}$ Theoretical calculations (DFT) support the involvement of encounter complexes, with geometries where the aromatic rings of the donor and the acceptor skew away from each other. The process leads to the $\alpha$-hydroxyalkyl radical (BTH) plus phenoxy or indolyl radicals with a quantum yield close to unity and takes place through a coupled electron-proton transfer. As enantiomerically pure chiral derivatives of BT, phenol and indole are easily accessible, these systems appeared in principle good candidates for investigating a possible stereodifferentiation in the formation and decay of encounter complexes.

Herein, we report experimental evidence supporting the formation of encounter complexes between $(R)$ or $(S)$-suprofen methyl ester (1), ${ }^{7}$ and $(R)$-tyrosine or $(R)$-tryptophan derivatives (2 and $\mathbf{3}$ in Chart 1). Determination of the pre-equilibrium constants

$\uparrow$ Electronic supplementary information (ESI) available: additional plots. See http://www.rsc.org/suppdata/cc/b5/b500697j/

*julia.perez@uv.es (Julia Pérez-Prieto)

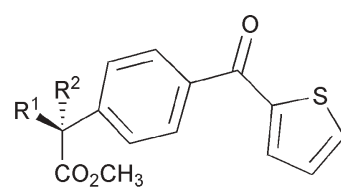

$(R)-1 \mathrm{R}^{1}=\mathrm{H}, \mathrm{R}^{2}=\mathrm{CH}_{3}$ (S) $-1 \mathrm{R}^{1}=\mathrm{CH}_{3}, \mathrm{R}^{2}=\mathrm{H}$

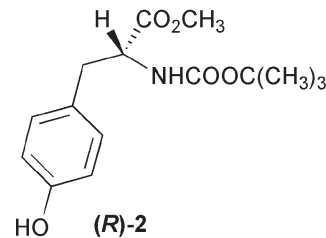

Chart 1 Structures of the employed acceptors and donors.

$\left(K_{\mathrm{EC}}\right)$ and the intrinsic decay rate constants $\left(k_{\mathrm{d}}\right)$ for each pair indicates a remarkable stereodifferentiation in both steps of the quenching process.

Laser flash photolysis of ketone 1 (Nd:YAG, $355 \mathrm{~nm}, 10 \mathrm{~ns}$ pulse) in deaerated acetonitrile or dichloromethane $\left(1.1 \times 10^{-3} \mathrm{M}\right)$ solutions provided the ketone triplet excited state with $\lambda_{\max }=600 \mathrm{~nm}$ (see Figs. S1 and S2 in supporting information $\dagger$ ), which decayed to the spectral baseline on the microsecond time scale $\left(k_{0}=4.2 \times 10^{5} \mathrm{~s}^{-1}\right)$. In the presence of phenol 2 or indole 3 the triplet decayed markedly faster, leading to the $\alpha$-hydroxyalkyl radical $\left(\lambda_{\max }=580 \mathrm{~nm}\right.$ and no absorption above $\left.620 \mathrm{~nm}\right)$ plus the phenoxy $\left(\lambda_{\max }=385-405 \mathrm{~nm}\right)$ or indolyl radicals $\left(\lambda_{\max }=520 \mathrm{~nm}\right)$ with high efficiency. This is shown in eqn. 2 and Figs. S3-S6 of the supporting information.

Kinetic evaluation of the quenching process was performed by monitoring the decay of the ketone triplet at $630 \mathrm{~nm}$ (where none of the resulting radicals exhibit significant absorption) in the presence of both types of donors. Fig. 1 shows the plot of the observed first-order rate constant for the decay of triplet $(\boldsymbol{S})-\mathbf{1}$ or $(\boldsymbol{R}) \mathbf{- 1}$ in dichloromethane versus the concentration of $(\boldsymbol{R}) \mathbf{- 2}$. Similar plots were obtained for the other ketone/quencher pairs, using either dichloromethane or acetonitrile as solvent (see supporting information; Figs. S7-S14 $\dagger$ ). Thus, a linear dependence of the observed first-order rate constant $\left(k_{\mathrm{obs}}=1 / \tau_{\text {obs }}\right)$ on quencher concentration was found at low concentrations (below $2 \mathrm{mM}$ for the indolic derivative or $5 \mathrm{mM}$ for Tyr derivative). The slopes provided the second-order rate constants $\left(k_{2}\right)$ for the quenching process (Table 1). The $k_{2}$ values for $(\boldsymbol{R})-\mathbf{3}$ were higher than for $(\boldsymbol{R})-\mathbf{2}$, in agreement with the lower oxidation potential of the former. ${ }^{8}$ In acetonitrile, where the hydrogen bonding accepting basicity is four times higher ( $\beta$ index 0.4 vs. 0.1 in 


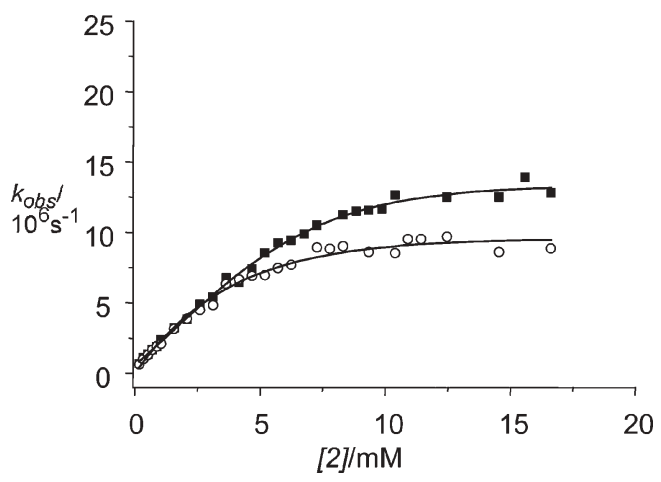

Fig. 1 Saturation behavior of the observed rate constant $\left(k_{o b s}\right)$ for the quenching of $(\boldsymbol{S})-\mathbf{1}(\bigcirc)$ and $(\boldsymbol{R})-\mathbf{1}(\boldsymbol{\square})$ triplet excited state by $(\boldsymbol{R})-\mathbf{2}$ in dichloromethane.

dichloromethane), ${ }^{9}$ the bimolecular hydrogen abstraction from phenol by BT triplet is retarded, due to a decreased concentration of free phenol; ${ }^{6}$ this explains the comparatively lower $k_{2}$ values found in this solvent when using $(\boldsymbol{R})-\mathbf{2}$ as quencher. As expected, ${ }^{6}$ such effect was not observed for the BT/indole pair.

$$
\begin{gathered}
\mathrm{S} \stackrel{h v}{\longrightarrow} \stackrel{\text { isc }}{\longrightarrow}{ }^{3} \mathrm{~S}^{*} \\
{ }^{3} \mathrm{~S}^{*}+\mathrm{HD} \stackrel{k_{2}}{\longrightarrow} \mathrm{SH}^{*}+\mathrm{D}^{*} \\
{ }^{3} \mathrm{~S} *+\mathrm{HD} \stackrel{{ }_{\mathrm{EC}}}{\rightleftharpoons}{ }^{3} \mathrm{~S} *----\mathrm{HD} \stackrel{k_{\mathrm{d}}}{\longrightarrow} \mathrm{SH}^{*}+\mathrm{D}^{*} \\
k_{\mathrm{obs}}=k_{2}[\mathrm{HD}]=K_{E C} k_{\mathrm{d}}[\mathrm{HD}]
\end{gathered}
$$

At higher donor concentrations the $k_{2}$ values did not increase linearly, but they rather approached a plateau, indicating the existence of a pre-equilibrium intermediate, i.e. the encounter complex between the triplet excited ketone and the aromatic donor (Fig. 1 and eqn. 3). ${ }^{10}$

The plots of $k_{\mathrm{obs}}$ vs. quencher concentration nicely show the saturation behaviour of the kinetics; unfortunately, it is not possible to obtain accurate values for $K_{\mathrm{EC}}$ and $k_{\mathrm{d}}$ from these plots. Rearranged equations are thus needed that allow the experimental data to be plotted in linear form. Therefore following Kochi's methodology for related cases, ${ }^{3}$ the curved kinetic plots were evaluated in a double-reciprocal representation following eqn. $5^{11}$ (see Fig. 2 for the $(\boldsymbol{R})-\mathbf{1} /(\boldsymbol{R})-2$ pair in dichloromethane).

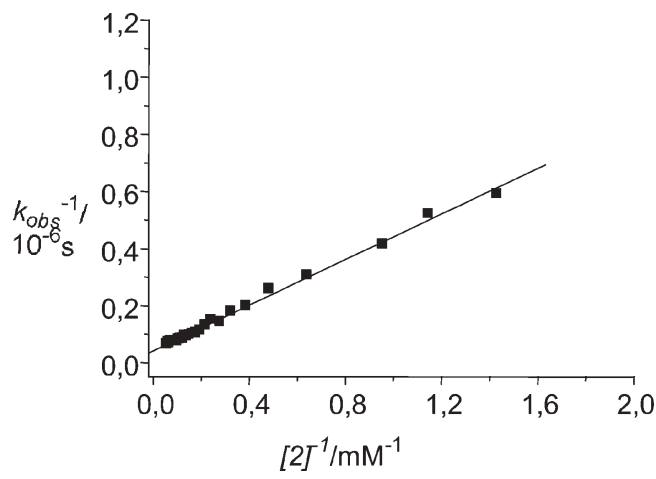

Fig. 2 Double reciprocal evaluation according to eqn. 5 for the quenching of $(\boldsymbol{R})-\mathbf{1}$ triplet excited state by $(\boldsymbol{R})-\mathbf{2}$ in dichloromethane.

The pre-equilibrium constants $\left(K_{\mathrm{EC}}\right)$ and the intrinsic decay rate constants $\left(k_{\mathrm{d}}\right)$ of the encounter complex were thus obtained for all pairs (see Table 1). ${ }^{10}$

$$
1 / k_{\mathrm{obs}}=1 / k_{\mathrm{d}}+1 /\left(K_{\mathrm{EC}} k_{\mathrm{d}}[\mathrm{HD}]\right)
$$

The $K_{\mathrm{EC}}$ values deviated considerably from the unity expected for the purely diffusional encounters. ${ }^{12}$ Taking into account that this constant depended on the effective approach distance between the donor and acceptor, the results indicated the formation of strong encounter complexes, except for the phenolic derivative in acetonitrile. The most striking result was the remarkable stereodifferentiation observed in some cases for both the formation and decay of the encounter complex (see curved kinetic plots for $(S)-1 /(R)-2$ and $(R)-1 /(R)-2$ diastereomeric pairs in Fig. 1). For the ketone/tryptophan pairs a considerably higher chiral recognition was observed in acetonitrile than in dichloromethane. A much less important solvent effect was observed for the ketone/tyrosine pairs (see Table 1).

In summary, the involvement of encounter complexes between both enantiomers of a $\pi, \pi^{*}$ triplet excited ketone and a chiral phenol or indole has been experimentally established. Determination of the pre-equilibrium constants $\left(K_{\mathrm{EC}}\right)$ and the intrinsic decay rate constants $\left(k_{\mathrm{d}}\right)$ for each diastereomeric pair has evidenced a significant stereodifferentiation in both steps of the quenching process, which depends on the solvent properties. Due

\begin{tabular}{|c|c|c|c|c|}
\hline Constants & $(R)-1 /(R)-2$ & $(S)-1 /(R)-2$ & $(R)-1 /(R)-3$ & $(S)-1 /(R)-3$ \\
\hline$k_{2} \times 10^{-9}\left(\mathrm{M}^{-1} \mathrm{~s}^{-1}\right)^{b}$ & $\begin{array}{l}0.209 \pm 0.008 \\
(2.30 \pm 0.09)\end{array}$ & $\begin{array}{l}0.232 \pm 0.008 \\
(2.13 \pm 0.08)\end{array}$ & $\begin{array}{c}1.75 \pm 0.08 \\
(2.86 \pm 0.09)\end{array}$ & $\begin{array}{l}1.64 \pm 0.06 \\
(2.9 \pm 0.1)\end{array}$ \\
\hline$K_{\mathrm{EC}}\left(\mathrm{M}^{-1}\right)^{c}$ & $\begin{array}{l}6.7 \pm 0.7 \\
(119 \pm 8)\end{array}$ & $\begin{array}{r}9.2 \pm 0.8 \\
(177 \pm 14)\end{array}$ & $\begin{array}{l}61 \pm 7 \\
(64 \pm 7)\end{array}$ & $\begin{array}{l}90 \pm 9 \\
(77 \pm 6)\end{array}$ \\
\hline$k_{\mathrm{d}} \times 10^{-7}\left(\mathrm{~s}^{-1}\right)^{d}$ & $\begin{array}{c}2.9 \pm 0.2 \\
(2.1 \pm 0.1)\end{array}$ & $\begin{array}{l}2.2 \pm 0.2 \\
(1.45 \pm 0.08)\end{array}$ & $\begin{array}{c}3.7 \pm 0.4 \\
(4.81 \pm 0.09)\end{array}$ & $\begin{array}{c}2.4 \pm 0.2 \\
(4.1 \pm 0.3)\end{array}$ \\
\hline$K_{\mathrm{EC}} k_{\mathrm{d}} \times 10^{-9}\left(\mathrm{M}^{-1} \mathrm{~s}^{-1}\right)^{e}$ & $\begin{array}{l}0.19 \pm 0.03 \\
(2.5 \pm 0.3)\end{array}$ & $\begin{array}{l}0.20 \pm 0.04 \\
(2.6 \pm 0.3)\end{array}$ & $\begin{aligned} & 2.2 \pm 0.5 \\
&(3.1 \pm 0.4)\end{aligned}$ & $\begin{array}{c}2.4 \pm 0.4 \\
\mathrm{z}(3.2 \pm 0.5)\end{array}$ \\
\hline
\end{tabular}
to the potential interest of these findings in connection with asymmetric photochemistry from the triplet excited state, current efforts are addressed to study the influence of substitution on the

Table 1 Kinetic parameters for the quenching of photoexcited $(\boldsymbol{R})-\mathbf{1}$ and $(\boldsymbol{S})-\mathbf{1}$ by $(\boldsymbol{R})-\mathbf{2}$ or $(\boldsymbol{R})-\mathbf{3}$ in acetonitrile and dichloromethane ${ }^{a}$

${ }^{a}$ Values in $\mathrm{CH}_{2} \mathrm{Cl}_{2}$ in parentheses. ${ }^{b}$ Rate constants for bimolecular quenching determined from the slopes of the initial linear portion of the kinetic plots (see Fig. 1). ${ }^{c}$ Equilibrium constants for encounter complex formation as determined using eqn. $5 .{ }^{d}$ Intrinsic rate constants for the encounter complex decay as determined using eqn. 5. ${ }^{e}$ Values determined from the slopes of the double-reciprocal plots (see Fig. 1) using eqn. 5. 
donor and the acceptor, as well as the polarity of the solvent, on stereodifferentiation.

Financial support by the Spanish Government (Project BQU2002-00377) and the Generalitat Valenciana (Grupos 03/082) are gratefully acknowledged. R.E.G and M.C. M-M thank Fundación José y Ana Royo for post-doctoral and predoctoral fellowships.

Julia Pérez-Prieto, ${ }^{* a}$ Raquel E. Galian, ${ }^{a}$ Maria C. Morant-Miñana ${ }^{a}$ and Miguel A. Miranda ${ }^{* b}$

${ }^{a}$ Departamento de Química OrgánicalICMOL, Universidad de Valencia, Av. Vicent Andrés Estellés s/n, 46100, Burjassot, Valencia, Spain.

E-mail: julia.perez@uv.es; Fax: +34-963544939

${ }^{b}$ Departamento de QuímicalInstituto de Tecnología Química

UPV-CSIC, Universidad Politécnica de Valencia, Camino de Vera s/n, 46071, Valencia

\section{Notes and references}

1 (a) S. Asaoka, T. Wada and Y. Inoue, J. Am. Chem. Soc., 2003, 125, 3008; (b) F. D. Lewis, L.-S. Li, T. L. Kurth and R. S. Kalgutkar, J. Am. Chem. Soc., 2000, 122, 8573; (c) G. J. Kavarnos, Photoinduced Electron Transfer; VCH: New York, 1993; (d) Y. Inoue, Chem. Rev., 1992, 92, 741; (e) L. M. Tolbert and M. B. Ali, J. Am. Chem. Soc., 1982, 104, 1742; (f) Y. Inoue, S. Takamuku, Y. Kunitomi and H. Sakurai, J. Chem. Soc., Perkin Trans. 2, 1980, 1672; $(g)$ W. R. Ware, D. Watt and J. D. Holmes, J. Am. Chem. Soc., 1974, 96, 7853; (h) B. Stevens, Adv. Photochem., 1971, 8, 161; (i) D. Rehm and A. Weller, Isr. J. Chem., 1970, 8, 259.

2 (a) T. Tahara and H. O. Hamaguchi, J. Phys. Chem., 1992, 96, 8252; (b) P. P. Levin, P. F. Pluzhnikov and V. A. Kuzmin, Chem. Phys., 1989,
137, 331; (c) H. Kobashi, M.-A. Funabashi, T. Kondo, T. Morita, T. Okada and N. Mataga, Bull. Chem. Soc. Jpn., 1984, 57, 3557; (d) H. Rau, Chem. Rev., 1983, 83, 535.

3 (a) S. M. Hubig and J. K. Kochi, J. Am. Chem. Soc., 1999, 121, 617; (b) R. Rathore, S. M. Hubig and J. K. Kochi, J. Am. Chem. Soc., 1997, 119, 11468.

4 (a) H. Saito, T. Mori, T. Wada and Y. Inoue, Chem. Commun., 2004, 1652; (b) J. Pérez-Prieto, A. Lahoz, F. Boscá, R. Martinez-Maña and M. A. Miranda, J. Org. Chem., 2004, 69, 374; (c) Y. Inoue, E. Matsushima and T. Wada, J. Am. Chem. Soc., 1998, 120, 10687.

5 (a) T. Yorozu, K. Hayashi and M. Irie, J. Am. Chem. Soc., 1981, 103, 5480; (b) S. Goto, S. Takamuku, H. Sakurai, Y. Inoue and T. Hakushi, J. Chem. Soc., Perkin Trans. 2, 1980, 1678.

6 J. Pérez-Prieto, F. Boscá, R. E. Galian, A. Lahoz, L. R. Domingo and M. A. Miranda, J. Org. Chem., 2003, 68, 5104.

7 Both enantiomers of suprofen were obtained by resolution of commercially available racemic suprofen using chiral HPLC chromatography [Kromasil 100TBB, $5 \mu \mathrm{m} 25 \times 1 \mathrm{~cm}$, a $60: 40$ solution of hexane: tert-butyl methylether (containing $0.1 \%$ of acetic acid) as eluent].

8 (a) S. V. Jovanovic and S. Steenken, J. Phys. Chem., 1992, 96, 6674; (b) G. Merényi, J. Lind and X. Shen, J. Phys. Chem., 1988, 92, 134.

9 Y. Marcus, Chem. Soc. Rev., 1993, 409.

10 For the concentrations used in this report, formation of electron donor-acceptor complexes in the ground state between suprofen methyl ester and the donors was not detectable by UV-vis spectroscopy.

11 This direct relationship in eqn. 5 is valid only when the natural decay of the ketone triplet $\left(k_{0}\right)$ is negligibly slow as compared to $k_{\mathrm{d}}$ and the pre-equilibrium is established much faster than the decay to the radicals.

12 A value of $c a .1$ has been estimated for $K_{\mathrm{EC}}$ in encounter complexes between uncharged species with a distance of $R=7 \AA$ : M. Z. Eigen, Phys. Chem. N.F., 1954, 1, 176 